\title{
Neurocognitive enhancement therapy with work therapy: Productivity outcomes at 6- and 12-month follow-ups
}

\author{
Morris D. Bell, PhD; ${ }^{1-2 *}$ Gary J. Bryson, PsyD; ${ }^{1-2}$ Tamasine C. Greig, PhD; ${ }^{2}$ Joanna M. Fiszdon, PhD; $^{1-2}$ \\ Bruce E. Wexler, MD $^{2}$ \\ ${ }^{1}$ Department of Veterans Affairs (VA) Connecticut Healthcare System, West Haven, CT; ${ }^{2}$ Department of Psychiatry, \\ Yale University School of Medicine, New Haven, CT
}

\begin{abstract}
Neurocognitive enhancement therapy (NET), which involves computerized cognitive training and other methods, has been shown to improve working memory and executive function in schizophrenia. In the present study, 145 outpatients with diagnoses of schizophrenia or schizoaffective disorder recruited from a Department of Veterans Affairs mental hygiene clinic and from a community mental health center were randomized to 6 months of paid work therapy (WT) or to NET+WT. Mixed random effects analyses revealed significant increase in hours worked and money earned over time for both conditions $(p<0.0001)$. NET+WT worked more hours than WT $(p<0.03)$, with differences emerging after rehabilitation. Responders to NET+WT worked the most during follow-up and tended to have more competitive-wage employment. Results indicate that work outcomes were enhanced by NET training. Effects were greatest for NET responders. Findings support the efficacy of cognitive training when it is integrated into broader rehabilitation programs.
\end{abstract}

Key words: cognition, cognitive remediation, functional outcomes, neuropsychology, psychiatric rehabilitation, psychosis, psychosocial rehabilitation, schizophrenia, vocational rehabilitation, work therapy.

\section{INTRODUCTION}

People with schizophrenia encounter many barriers to successful reentry into work life. One of the greatest barriers has been the availability of appropriate opportunities with sufficient accommodations and supports. The Amer- icans with Disabilities Act offers legal remedies to egregious violations of rights, but the stigma associated with severe mental illness and some of the self-stigmatizing features of the illness have slowed progress in the provision of work services for the mentally ill. Other barriers outside the person that influence vocational outcomes include unintended disincentives of most entitlement programs. Moreover, barriers inside the person, directly or indirectly related to the illness, impede vocational success.

\footnotetext{
Abbreviations: $\mathrm{CWT}=$ compensated work therapy; $d f=$ degrees of freedom; fMRI = functional magnetic resonance imaging; $\mathrm{IT}$ = incentive therapy; NET = neurocognitive enhancement therapy; NS = not significant; SCID-I = Structured Clinical Interview for Diagnostic and Statistical Manual of Mental Disorders, 4th Edition, Axis I disorders; $\mathrm{SD}$ = standard deviation; $\mathrm{SE}=$ supported employment; VA = Department of Veterans Affairs; VACHS = Department of Veterans Affairs Connecticut Healthcare System; VCRS = Vocational Cognitive Rating Scale; WBI = Work Behavior Inventory; WT = work therapy.

This material was based on work funded by the Department of Veterans Affairs, Rehabilitation Research and Development Service, grants D2128 and D5236-R (Dr. Bell), and a Career Development Award from the National Institute of Mental Health (Dr. Wexler).

*Address all correspondence to Morris Bell, PhD; Psychology Service 116B, VA Connecticut Healthcare System, West Haven, CT; 203-932-5711, ext. 2281; fax: 203-937-4883. Email: morris.bell@yale.edu DOI: 10.1682/JRRD.2005.03.0061
} 
Cognitive impairment may be one of the most influential of these barriers.

Many investigations, including our own, have found strong associations between cognitive deficits in schizophrenia and vocational function [1-6]. A recent review concluded that prospective, cross-sectional, and retrospective studies support the relationship of cognitive deficits to work outcomes, but noted that vocational rehabilitation programs may weaken the association by compensating or accommodating these impairments [7]. In the present study, we provided a paid work program that thereby removed lack of opportunity as a barrier to working, and we offered appropriate accommodations and support that might attenuate the impact of cognitive impairments. We then evaluated the effects of adding a comprehensive cognitive training program, neurocognitive enhancement therapy (NET), that included repetitive practice on progressively more difficult computerized attention, memory, and executive function tasks aimed at addressing these common cognitive impairments in schizophrenia. Patients were randomly assigned to receive work therapy (WT) that was enhanced by a weekly workers meeting that included biweekly work feedback [8] or to receive WT plus NET (NET+WT). In addition to the training of elemental cognitive functions, NET added biweekly feedback on cognitive performance in the workplace to the other work performance feedback and a weekly social information-processing group. These treatment elements provided ongoing opportunities to incorporate elemental neurocognitive gains into more complex cognitive operations.

A number of review articles on cognitive remediation have been published, and most find support for its efficacy in improving task performance [9-14]. However, the literature lacks studies that examine generalizability beyond test improvement or duration of effects. Previously, we reported on cognitive outcome data after 5 months of treatment for the first 65 patients enrolled in the present study [15]. Subjects who received NET+WT showed significantly greater improvements on neuropsychological tests of executive function and working memory than those subjects who received WT alone. Moreover, a greater proportion of NET+WT subjects improved to normal levels of performance on these tasks than did WT subjects. In subsequent articles, we reported that severely cognitively impaired patients showed improvement comparable with that of less severely impaired patients on working memory tasks [16] and that more than half of patients with below-normal performance on working memory tasks could achieve normal levels of performance after NET training [17]. Moreover, these gains endured 6 months after training was completed [18].

While durability of effects and generalization to untrained but similar cognitive tasks to those used in NET supported the efficacy of cognitive remediation, our primary concern was whether greater cognitive gains would yield important functional outcomes, particularly once training was completed. We hypothesized that patients receiving NET+WT would show greater productivity during the 6 months following training than those who received WT alone and that those patients who responded to training with normalization of their working memory performance would show the greatest gains in productivity.

\section{METHODS}

\section{Subjects}

Between January 19, 1998, and February 25, 2003, 151 patients participated, all with schizophrenia or schizoaffective disorder as determined by $\mathrm{PhD}$ psychologists using the Structured Clinical Interview for Diagnostic and Statistical Manual of Mental Disorders, 4th edition (DSM-IV), Axis disorders, (SCID-I) procedures [19]. The patients were referred by their clinicians and were in treatment at the Department of Veterans Affairs (VA) Connecticut Healthcare System (VACHS), West Haven, Connecticut, or at the Connecticut Mental Health Center at Yale University, New Haven, Connecticut. SCID-I training was provided by the National Center for the Biological Study of Schizophrenia located at VACHS, and on those occasions where diagnosis was in doubt, the interview data were reviewed by senior investigators at the center and consensus reached. All patients provided informed, written consent in accordance with procedures approved by the local VA institutional review board.

Patients were considered not sufficiently stable to participate if they had been hospitalized, changed psychiatric medications or housing, had an episode of drug abuse within the past 30 days, or had a Global Assessment of Functioning score of 30 or below. Known neurological disease and developmental disability were cause for exclusion. Randomization was stratified by severity of cognitive impairment determined by six key neuropsychological variables [16] and by previous work experience 
(1 year or more of continuous employment) by creating four randomization tables from a random number generator. Neuropsychological data for stratification were based on the intake assessment of attention, verbal learning, figural memory, executive function, thought disorder, and affect recognition [16]. These tables were kept out of the sight of the investigators by the statistician who made assignments to condition. Of the 151 patients randomized, 6 withdrew from the study prior to participation in the intervention ( 3 from NET+WT and 3 from WT), so that 145 patients became our intent-to-treat sample for this randomized clinical trial. Patient background and illness characteristics are displayed in Table 1, showing no significant differences between conditions on those variables at intake. Follow-up rate at 6 months from baseline was 94 percent, and at 12 months, 89 percent. Follow-up rates by condition did not differ significantly. Patient background and illness characteristics of the follow-up samples did not differ significantly by condition. Of those subjects with follow-up at 6 months, nine subjects did not have pre- and post-digits recall performance testing, because the procedure was added after these subjects had entered the study. These nine subjects are included in all analyses except those involving the interaction of digits performance and functional outcomes because their digits performance data were not obtained.

\section{Measures of Productivity}

Hours worked and dollars earned were recorded directly from WT payrolls during the active intervention. Money earned from participating in research procedures including cognitive training was not included in the sum of dollars earned. Although community work for pay was rare during the period of active intervention, these hours and dollars were also recorded, either from pay slips or from subject reports. Most subjects who continued to work after the 6 months of active intervention did so through VA work services either in incentive therapy (IT), which pays half-minimum wage and places patients in accommodating settings, or in compensated WT (CWT), which pays competitive wages for work performed through subcontracts. These programs provide work opportunity, but much less individual support than subjects received while in WT. WT is the IT program plus the supports provided by the research study. Although subjects would be able to continue working in the medical center after the intervention, they no longer attended the WT workers meeting or had individual
Table 1.

Mean \pm standard deviation for background and treatment characteristics of NET+WT and WT patients.

\begin{tabular}{lcc}
\hline \multicolumn{1}{c}{ Variable } & $\begin{array}{c}\text { NET+WT } \\
(\boldsymbol{n}=\mathbf{6 9 )}\end{array}$ & $\begin{array}{c}\text { WT } \\
(\boldsymbol{n}=\mathbf{7 6})\end{array}$ \\
\hline Age & $42.0 \pm 9.5$ & $43.5 \pm 8.3$ \\
Gender, Male (\%) & $53.0 \pm 77.0$ & $63.0 \pm 83.0$ \\
Marital Status (\%) & & \\
Single & $47.0 \pm 68.0$ & $46.0 \pm 61.0$ \\
Married & $6.0 \pm 9.0$ & $12.0 \pm 16.0$ \\
Divorced & $15.0 \pm 22.0$ & $17.0 \pm 22.0$ \\
Widowed & $1.0 \pm 1.0$ & $1.0 \pm 1.0$ \\
Race & & \\
Caucasian & $43.0 \pm 63.0$ & $48.0 \pm 63.0$ \\
African American & $23.0 \pm 33.0$ & $23.0 \pm 30.0$ \\
Hispanic & $1.0 \pm 1.0$ & $3.0 \pm 4.0$ \\
Asian & $2.0 \pm 3.0$ & $2.0 \pm 3.0$ \\
WAIS-Global & $87.9 \pm 12.5$ & $89.9 \pm 13.7$ \\
Education & $13.2 \pm 2.0$ & $13.2 \pm 2.1$ \\
Age of Onset & $22.5 \pm 7.8$ & $22.7 \pm 7.3$ \\
Age at 1st Hospitalization & $25.6 \pm 7.4$ & $26.2 \pm 7.5$ \\
Lifetime Hospitalizations & $8.2 \pm 11.6$ & $8.6 \pm 7.9$ \\
PANSS Components & & \\
Positive & $17.0 \pm 5.8$ & $17.4 \pm 5.1$ \\
Negative & $19.7 \pm 5.5$ & $19.6 \pm 5.4$ \\
Cognitive & $18.3 \pm 5.5$ & $17.2 \pm 5.2$ \\
Hostility & $7.9 \pm 3.5$ & $8.0 \pm 3.2$ \\
Emotional Discomfort & $10.7 \pm 3.2$ & $11.4 \pm 2.7$ \\
PANSS Total & & \\
Antipsychotic Medications $(\%)$ & & \\
Typical & & \\
Atypical & & \\
Both & & \\
None & & \\
Medication Dose & & \\
(CPZ equivalent) & & \\
*No statistically significant differences between conditions & were found. \\
NET = neurocognitive enhancement therapy. & \\
WT = work therapy. & & \\
WAIS = Wechsler Adult Intelligence Test, revised. & \\
PANSS = Positive and Negative Syndrome Scale. & \\
CPZ = chlorpromazine. & & \\
\hline
\end{tabular}

counseling for work-related problems. Thus, there was an immediate loss of these supports when they completed the 6 months of WT. Once subjects concluded their 6 months of active intervention, they had very little contact with research staff until follow-up, 6 months later. Any contact was informal and unrelated to assignment to condition. No data were collected on the amount or type of vocational services provided by other vocational agencies during follow-up. 
Work status was categorized as competitive-wage employment (CWT or competitive community employment), IT or other transitional work for less than minimum wage, or unemployment. Volunteer work or going to school was not considered employment. Rates of competitive-wage employment were based on CWT or community employment and did not include IT.

\section{Description of Intervention}

\section{Work Therapy}

WT consisted of (1) payment for work activity at the rate of $\$ 3.40 / \mathrm{h}$ for up to $15 \mathrm{~h} /$ week, with increasing bonus pay (\$3.90 to $\$ 8.40$ ) for 16 to $20 \mathrm{~h}$; (2) job placement at the VA medical center; (3) a workers meeting offering support, problem solving, detailed work performance feedback based on the Work Behavior Inventory (WBI) [20-21], and goal setting; (4) a job coach for job-related difficulties and individual vocational counseling; and (5) referral to other vocational services. The most common work sites were in dietetics, mailroom, grounds, maintenance, patient transport, and medical administration, with duties similar to those of entry-level employees who were supervised by regular medical center personnel.

\section{Neurocognitive Enhancement Therapy}

NET consisted of (1) feedback from the Vocational Cognitive Rating Scale (VCRS) [22] in the workers meeting, (2) cognitive exercises for up to 5 h each week for 26 weeks, and (3) a weekly social processing group. Patients were paid for doing cognitive exercises at $\$ 3.40 / \mathrm{h}$, with increasing bonus pay ( $\$ 3.90$ to $\$ 8.40$ ) for reaching a maximum of $5 \mathrm{~h}$ of cognitive training. They could also work up to $15 \mathrm{~h}$ in WT, for a combined maximum of $20 \mathrm{~h}$ of productive activity each week.

\section{Vocational Cognitive Rating Scale Feedback}

VCRS feedback was given on a biweekly schedule (at the same time as patients receive the WBI feedback) and consisted of ratings of attention, memory, and executive function from their job. Patients were also encouraged to develop goals based on their VCRS feedback.

\section{Cognitive Exercises}

Cognitive exercises involved repeated practice on computer-based exercises for attention, memory, and executive function (adapted to our specification by Bracy [23]) and a dichotic listening task. Patients attended, on average, two to three sessions each week. Cognitive exercises used a modified form of Bracy's Psychological Software Services CogReHab software [23], a multimedia cognitive rehabilitation software designed for use with individuals with compromised brain function. Four tasks were modified from this software package and used as the first step in the curriculum: two tasks (Visual Tracking I and Visual Tracking II) for training sustained visual attention and two tasks (Sequence Recall: Digits-Visual and Sequence Recall: Words-Visual) for training verbal memory. A fifth task (Pyramids) was used to train executive functions. Task parameters were initially made easy enough for each patient to do well. As soon as the patient was able to achieve 90 percent accuracy at a given difficulty level, the task was made more difficult following a prearranged hierarchy. A dichotic listening task was added to train auditory attention and memory in the presence of distracter sounds. Other tasks were added as patients advanced, including a task of multiple simultaneous attention and several problem-solving tasks. Details of the tasks are available in our earlier report [15]. Patients averaged $47.1 \pm 40.3$ standard deviation (SD) cognitive training sessions during the active intervention.

\section{Social Information Processing Group}

The weekly group for social information processing was based on a group exercise from the Traumatic Brain Injury program of Ben-Yishay et al. [24]. One subject each week prepared an oral presentation with staff assistance that was delivered to the group. Each group member was required to ask a question and give specific feedback to the presenter in a manner similar to other social skills groups. Three topics were given sequentially over the 6 months: "My job," "A day at work," and "What I've learned." This highly structured group experience demanded verbal expression, verbal memory, and executive function, as well as social information processing, affect recognition, and interpersonal sensitivity.

\section{Similarities and Differences with Other Cognitive Rehabilitation Methods}

NET was designed to be an intensive and comprehensive approach to cognitive retraining built upon evidence of neuroplasticity and experience-dependent changes in brain function. The adjective neurocognitive was chosen to indicate that the primary target of training was elemental neurocognitive mechanisms, and results of a preliminary functional magnetic resonance imaging (fMRI) study suggest evidence of a correspondence between improvement 
in neurocognition and favorable changes in brain function [25]. NET contrasts with other types of training that emphasize executive [26-27], compensatory [28-29], cognitive-behavioral [30-31], or gistful learning [32-33] training. However, all these approaches may share common features, and whether the presumed mechanism of change for each method is actually responsible for the favorable outcomes that have been reported remains largely unknown. In this study, NET was enhanced with group experiences that may have exercised executive functions, suggested compensatory strategies, addressed negative cognitions, and engaged social learning.

\section{Defining Responders to NET}

One way to test the link between the cognitive intervention and improved productivity is for one to determine whether differential outcomes are found for those patients who responded adequately to the training. In a previous study, we collected data on two attention and two verbal recall tasks used in cognitive training from a community sample with no identified psychiatric or neurological illness so that we could create performance norms [17]. Our intent was to use these norms to identify subjects who responded to the training sufficiently to achieve the clinically meaningful marker of normal range performance. We established from these data one SD below the mean as a minimum cutoff criterion for normal range performance. We applied that criterion to the performance data from our sample at intake and at the conclusion of the active intervention (6-month follow-up) to place patients into four categories: (1) Normal Performers (those who had normal performance at intake and had normal performance at follow-up), (2) Normalizers (those who had below-normal performance at intake but achieved normal performance at follow-up), (3) Below Normal Performers (those who had belownormal performance at intake and follow-up), and (4) Decreased Performers (those who had normal performance at intake but below-normal performance at fol- low-up). Similar classification methods have been used in studies of learning potential in schizophrenia [34-36].

$\mathrm{NET}+\mathrm{WT}$ subjects compared to WT subjects had a significantly greater proportion of subjects classified as Normalizers on the two verbal recall tasks, and we selected the task that showed the greatest improvement, the Digits Recall task, to indicate that a patient had been a responder to cognitive training. These analyses were all performed prior to the collection of work outcome data, and the task was therefore established prior to and independently from the analyses in this article. As seen in Table 2, for the 60 subjects in NET+WT, 37 percent were Normalizers as compared with 12 percent of the 67 subjects in WT (McNemar's $Q=9.85, p<0.005$ ), and 52 percent of NET+WT and 40 percent of WT were in the normal range at follow-up. Some difference in baseline performance was found between conditions due to random factors, but it was not significant (NS) $\chi^{2}{ }_{1}=3.51, p<$ $0.10)$. For analyses testing hypotheses related to being a responder to cognitive training, we needed to be concerned that contrasts account for the presence of Normal Performers in both conditions. To do otherwise would bias the analyses toward the experimental condition. Therefore, we analyzed the productivity outcomes using an interaction between condition and having a normal digits performance at follow-up. This interaction would allow us to learn whether normal digits performers at follow-up who had the cognitive training (most of whom became normal performers only after the training) differed from normal performers at follow-up who did not have the training.

\section{Data Analyses}

We employed an "intent-to-treat" analysis that used all patients randomized to condition regardless of degree of participation. Outcome measures were analyzed by a mixed models with repeated measure method. The continuous outcome measures (hours and dollars earned) served as dependent variables in their own models, and

Table 2.

Subjects with digits recall performance that was normal at intake and 6-month follow-up (Normal Performers), normal at intake but not at followup (Decreased Performers), not normal at intake but normal at follow-up (Normalizers), or not normal at intake or follow-up (Below-Normal Performers).

\begin{tabular}{lcccc}
\hline \multicolumn{1}{c}{ Condition } & $\begin{array}{c}\text { Normal } \\
\text { Performers }\end{array}$ & $\begin{array}{c}\text { Decreased } \\
\text { Performers }\end{array}$ & Normalizers & $\begin{array}{c}\text { Below-Normal } \\
\text { Performers }\end{array}$ \\
\hline NET + WT, $n(\%)$ & $9(15)$ & $5(8)$ & $22(37)$ & $24(40)$ \\
WT, $n(\%)$ & $19(28)$ & $7(10)$ & $8(12)$ & $33(49)$ \\
\hline${ }^{*} \chi^{2}{ }_{3}=11.51, p<0.009$. & & & \\
NET $=$ neurocognitive enhancement therapy, $\mathrm{WT}=$ work therapy. & & \\
\hline \hline
\end{tabular}


condition (NET+WT or WT) and time served as fixed effects, with subject as a random intercept effect. Intake, 6 months, and 12 months were the repeated time points. Considering the possibility of interactions of digits performance status (normal performance or not normal at 6 month follow-up) with condition and time, we also included condition-by-digits performance-by-time interaction terms in the model. We used a banded main diagonal covariance structure to fit the model, chosen by comparing the Aikake information criteria of different covariance structures. The mean of each outcome variable for digits performance status, intervention group (NET+WT, WT), and observation point along with the 95 percent confidence intervals were estimated by the model just described with weighted least-square method. All statistics analyses were performed in SAS version 8.2 [37]. A $p$-value of 0.05 (two-tailed) was used as the level of significance for all tests. Bonferroni correction was used for multiple comparisons.

We used the Mantel-Haenszel test to evaluate the association between the intervention condition and having competitive-wage employment in the first year of follow-up. Using two levels of work type (competitivewage or not competitive), we used the Breslow-Day test to compare the odds ratio for the likelihood of having competitive-wage employment.

\section{RESULTS}

\section{Hours Worked}

Hours worked using mixed modeling shows a significant time effect $\left(F_{2,104}=28.41, p<0.001\right)$ and time-bycondition interaction $\left(F_{2,104}=3.68, p<0.03\right)$. Time effects are significant from intake to 6-month follow-up $\left(t_{(83.7)}=6.21, p<0.0001\right)$ and intake to 12-month follow-up $\left(t_{(105)}=6.46, p<0.0001\right)$, but not from 6-month to 12-month follow-up $\left(t_{(115)}=-0.75, p=\mathrm{NS}\right)$. The time- by-condition interaction is NS from intake to 6 months, but becomes significant at the 12 month follow-up. The means suggest that the interaction occurs from 6 months to 12 months (Figure).

When results include the interaction for normal digits performance status at the end of the intervention (Table 3), a significant time-by-condition-by-normal digit status interaction occurs $\left(F_{10,244}=2.08, p<0.026\right)$ with NET+WT normal digits performers showing the greatest increase in hours worked from 6-month to 12-month follow-up. From 6-month to 12-month follow-up, the NET+WT patients with normal digits performance worked significantly more hours compared with WT subjects with normal digits performance $\left(t_{(102)}=3.63, p<0.001\right)$.

\section{Dollars Earned}

Dollars earned showed a similar trend to that of hours worked but with greater variance because, although most subjects earned the same hourly rate, a few subjects

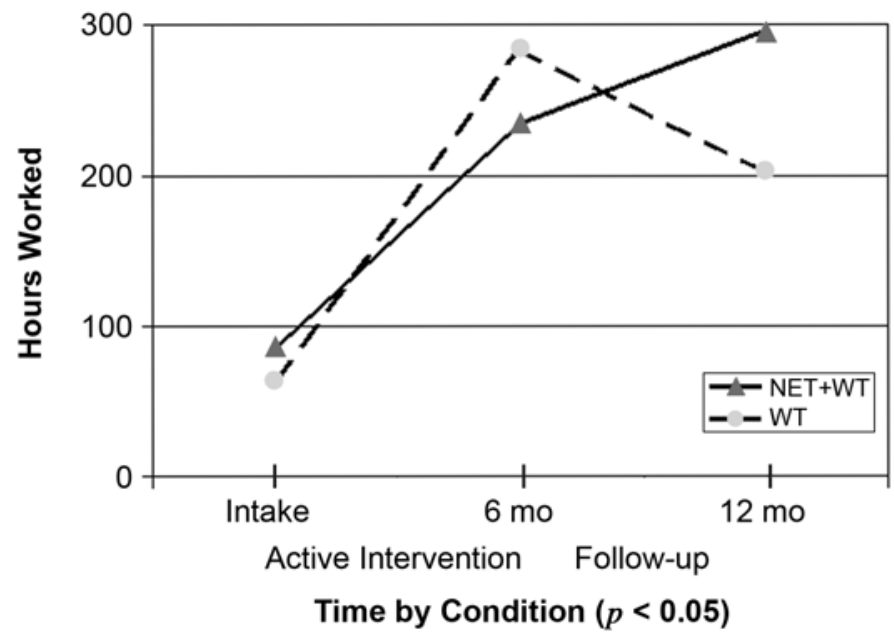

Figure.

Hours worked by condition for 6 months prior to intake, 6 months of active intervention, and 6 months of follow-up.

Table 3.

Least-squared mean \pm standard error by condition and normal digits performance status for hours worked during 6 months prior to intake, intake to 6 months (end of intervention), and 6 months to 12 months of NET+WT and WT subjects.

\begin{tabular}{clccc}
\hline Condition & Normal Digits Status & Intake & 6 Months & 12 Months \\
\hline NET+WT & Normal $(n=31)$ & $86.5 \pm 37.8$ & $225.4 \pm 37.8$ & $391.6 \pm 39.6$ \\
& Below normal $(n=29)$ & $65.8 \pm 39.1$ & $170.0 \pm 39.1$ & $215.7 \pm 41.9$ \\
WT & Normal $(n=27)$ & $54.4 \pm 41.3$ & $274.1 \pm 41.3$ & $129.5 \pm 42.9$ \\
& Below normal $(n=40)$ & $105.8 \pm 33.3$ & $247.4 \pm 33.3$ & $258.1 \pm 34.1$ \\
\hline
\end{tabular}


earned extra money outside of WT or went on to get better paying jobs during the 6-month follow-up period. We used the same mixed-model strategy that we used for hours to analyze dollars earned. Dollars earned shows a significant overall time effect $\left(F_{2,269}=15.14, p<0.0001\right)$. Time effects are significant from intake to 6- month follow-up $\left(t_{(269)}=-4.65, p<0.0001\right)$ and from intake to 12 month follow-up $\left(t_{(269)}=-4.79, p<0.0001\right)$, but not from 6 month to 12 month follow-up $\left(t_{(269)}=-0.40, p=\right.$ NS). We observed a NS time-by-condition interaction $\left(F_{2,269}=0.85, p=\mathrm{NS}\right)$.

When results include the interaction for normal digits performance status at the conclusion of the intervention (Table 4), the time-by-condition-by-normal digit status interaction was NS. However, when the dollars earned for the NET+WT normal digits performers were compared with those for the WT normal digits performers over the three time points, a significant difference in earnings was found $\left(F_{1,261}=5.52, p<0.02\right)$. From 6 -month to 12-month follow-up, the NET+WT subjects who had achieved normal digits performance earned \$481.00 more than the average of all other subjects $\left(t_{(267)}=1.90\right.$, $p<0.059$ ) and they earned $\$ 795.18$ more than the WT subjects with normal digits performance $\left(t_{(267)}=5.52\right.$, $p<0.02)$.

\section{Work Status}

Work status at follow-up was categorized as competitive-wage employment (minimum wage or better employment in either CWT or community employment), IT, or not employed. For the entire sample, the number of subjects doing some form of productive activity for pay increased from 34 percent during the 6 months prior to intake to 70 percent during the 6 months after the intervention $\left.\chi^{2}{ }_{1}=37.34, p<0.001\right)$. NET+WT condition had a higher percentage of patients having competitive-wage employment (32\% vs $24 \%, p=\mathrm{NS})$. When NET+WT participants who achieved normal digits performance were compared with their counterparts in WT, the odds ratio of being competitively employed was suggestive but NS (2.44, 95\% confidence interval $=0.71,8.4 ; p=$ $0.15)$

\section{CONCLUSIONS}

Offering people with schizophrenia or schizoaffective disorder the opportunity to work for pay resulted in dramatic increases in their productive activity and earnings, and these effects continued during the 6 months that followed the active rehabilitation intervention. Approximately one-third of the patients had engaged in some type of productive activity for pay during the 6 months prior to intake, but more than two-thirds participated in paid work in the 6 months that followed the intervention. This finding shows that providing appropriate opportunities for patients to work is an important intervention for improving productivity.

This study primarily determined whether adding cognitive remediation to a work program could enhance functional outcomes. Patients receiving NET+WT showed the same productivity during the active intervention period as those receiving WT alone, but during the 6-month follow-up period, those receiving NET+WT worked significantly more hours.

The fact that differences emerged only after the completion of 6 months of cognitive remediation suggests several interpretations. One may be that a certain amount of intervention is required to see effects (for example, 40 sessions) and/or that the intervention must continue for a certain amount of time (for example, 6 months). We postulated that neurocognitive training promotes neuroplastic brain changes, and if so, time as well as experience may be

Table 4.

Least-squared mean \pm standard error by condition and normal digits performance status for dollars earned during the 6 months prior to intake, intake to 6 months (end of intervention), and 6 months to 12 months of NET+WT and WT subjects.

\begin{tabular}{clrrr}
\hline Condition & Normal Digits Status & Intake & 6 Months & 12 Months \\
\hline NET+WT & Normal $(n=31)$ & $426.45 \pm 204.0$ & $1063.59 \pm 143.0$ & $1402.00 \pm 533.0$ \\
& Below Normal $(n=29)$ & $322.48 \pm 118.0$ & $959.08 \pm 134.0$ & $915.92 \pm 220.0$ \\
WT & Normal $(n=27)$ & $435.00 \pm 174.0$ & $1187.62 \pm 132.0$ & $606.82 \pm 271.0$ \\
& Below Normal $(n=40)$ & $278.63 \pm 146.0$ & $1142.04 \pm 117.0$ & $1108.16 \pm 242.0$ \\
\hline
\end{tabular}

NET = neurocognitive enhancement therapy. 
required to reorganize and consolidate neuropathways associated with behavioral changes such as improved attention, memory, and executive function. However, psychosocial interventions, in general, may take 6 months or longer to show improvements in schizophrenia populations, and Hogarty et al [32] have reported improvements in function that occurred only after 2 years of intervention. A third possibility is that differential effects were masked because the patients in WT were getting enriched supports during the active intervention that partially compensated for their cognitive deficits. When those supports were removed, differences emerged.

The NET+WT intervention had three components not shared by the WT condition: the neurocognitive training, feedback and problem-solving about cognitive impairments on the job, and the social information processing group. Each may have made its own contribution, and they may have worked synergistically as well. For example, improved attention and problem-solving from the neurocognitive training may have made taking fuller advantage of the other interventions possible. The group, which was designed to provide training in verbal expression using social skills training techniques, also gave patients an opportunity to express the meaning of their work experience and in so doing may have helped them to revise their view of themselves from sick and disabled to more functional. Changes in self-narrative may be necessary for people to keep working when they encounter frustrations or obstacles [38-41]. Postulating these mechanisms remains speculative, except regarding neurocognitive training for which we have some evidence of a direct relationship.

The hypothesized link between cognitive remediation and improved outcomes is supported by the finding that those patients who received NET+WT and responded by having normalized digits recall showed the best outcomes during the 6 month follow-up period. They showed the greatest increase in hours, and they worked significantly more hours than patients who had normal digits performance and WT only. They also earned more money than the average of all other patients (although statistically NS) and significantly more than WT patients with normal digits performance. They also had the most favorable odds ratio (although statistically NS) for having competitive-wage employment during the followup period.

Normal digits performers in the WT condition had slightly poorer work outcomes at 12 months than their below normal digits performers in the same condition, and this is a little surprising because working memory in general is associated with better vocational outcomes and because normal digits performers in NET+WT had the best vocational outcomes. We cannot explain why normal digits performers in WT conditions declined in work hours and so we must assume that some random factors were involved. This difference between conditions on vocational outcomes for below normal versus normal digits performer at follow-up underscores the point that many of the NET+WT patients had become normal digits performers only after participating in neurocognitive training. Thus, the meaning of being a normal digits performer at follow-up is quite different for the two conditions. For the NET+WT condition, it indicated a response to NET.

The findings of this study support the hypothesis that neurocognitive training may improve work outcomes, but this claim has several restrictions. As mentioned previously, NET combined several interventions so that it cannot be stated that the neurocognitive training would have produced the same effects without the other constituents of NET. WT for both conditions was combined with a previously demonstrated enhancement-the use of WBI feedback and goal-setting in weekly group meetings [8]. This means that NET was interacting with the feedback intervention, which may have boosted NET's influence on outcome. Indeed, we cannot know from this study whether NET added to a CWT program would have yielded the same results. However, the recommended practice of psychosocial rehabilitation is to integrate many efficacious interventions in an algorithm sensitive to individual deficits and aimed at individual outcomes [42]. Thus, sorting out the specific contributions of component interventions, while scientifically important, may be less valuable to the field than knowing whether the whole approach benefits patients. Finally, this study did not include a no-treatment control, so conclusions about the benefits of providing WT are limited to the quasiexperimental procedure of examining pre- and post-rates of work activity.

Since the time that this study was planned and executed, supported employment (SE) has been recognized as the preferred evidence-based method for providing work services [43]. In an ongoing study based at a community mental health center, we are testing whether NET+SE enhances work outcomes when compared with SE alone. In this 12-month intervention with a 12-month follow-up, preliminary findings show no differences 
between condition during the active intervention but significantly better vocational outcomes for NET+SE during the year that followed [44-45], a finding consistent with that of the current study.

The current study did not include neuroimaging to determine how NET+WT may have affected brain function or structure. As cognitive remediation of various types become more common in psychiatric rehabilitation, investigating the underlying mechanisms of action will be an important scientific challenge. In particular, we hypothesize a process that uses the brain's latent potential for restorative neuroplastic changes, whereas other approaches hypothesize compensatory mechanisms by underused alternative neuropathways or by environmental manipulations and accommodations. In our ongoing study, we are gathering fMRI images before and after NET and plan to compare them with normal images on the same tasks. This should help us determine the relationship between improvement in neurocognitive performance and the underlying brain changes related to this improvement.

\section{REFERENCES}

1. Green MF. What are the functional consequences of neurocognitive deficits in schizophrenia? Am J Psychiatry. 1996; 153(3):321-30.

2. Green MF, Kern RS, Braff DL, Mintz J. Neurocognitive deficits and functional outcome in schizophrenia: are we measuring the "right stuff"? Schizophr Bull. 2000;26(1): 119-36.

3. Liberman R. "Rate-Limiting" factors in work capacity in schizophrenia: Psychopathology and neurocognitive deficits. Presented at Vocational Rehabilitation Research Colloquium Conference; 1996 Apr 17-18; Boston (MA).

4. Bell MD, Bryson GJ. Work rehabilitation in schizophrenia: Does cognitive impairment limit improvement? Schizophr Bull. 2001;27(2):269-79.

5. Lysaker PH, Bell MD, Beam-Goulet J. Wisconsin card sorting test and work performance in schizophrenia. Psychiatry Res. 1995;56(1):45-51.

6. McGurk SR, Meltzer HY. The role of cognition in vocational functioning in schizophrenia. Schizophr Res. 2000; 45(3):175-84.

7. McGurk SR, Mueser KT. Cognitive functioning, symptoms, and work in supported employment: A review and heuristic model. Schizophr Res. 2004;70(2-3):147-73.

8. Bell MD, Lysaker PH, Bryson GJ. A behavioral intervention to improve work performance in schizophrenia: Work behavior inventory feedback. J Vocat Rehabil. 2003;18(1): 43-50.

9. Kurtz MM, Moberg PJ, Gur RC, Gur RE. Approaches to cognitive remediation of neuropsychological deficits in schizophrenia: A review and meta-analysis. Neuropsychol Rev. 2001;11(4):197-210.

10. Twamley EW, Jeste DV, Bellack AS. A review of cognitive training in schizophrenia. Schizophr Bull. 2003;29(2):359-82.

11. Bellack AS, Gold JM, Buchanan RW. Cognitive rehabilitation for schizophrenia: Problems, prospects, and strategies. Schizophr Bull. 1999;25(2):257-74.

12. Rund BR, Borg NE. Cognitive deficits and cognitive training in schizophrenic patients: A review. Acta Psychiatr Scand. 1999;100(2):85-95.

13. Pilling S, Bebbington P, Kuipers E, Garety P, Geddes J, Martindale B, Orbach G, Morgan C. Psychological treatments in schizophrenia: II. Meta-analyses of randomized controlled trials of social skills training and cognitive remediation. Psychol Med. 2002;32(5):783-91.

14. Suslow T, Schonauer K, Arolt V. Attention training in the cognitive rehabilitation of schizophrenic patients: A review of efficacy studies. Acta Psychiatr Scand. 2001;103(1):15-23.

15. Bell MD, Bryson GJ, Greig T, Corcoran C, Wexler BE. Neurocognitive enhancement therapy with work therapy: Effects on neuropsychological test performance. Arch Gen Psychiatry. 2001;58(8):763-68.

16. Bell MD, Bryson GJ, Wexler BE. Cognitive remediation of working memory deficits: Durability of training effects in severely impaired and less severely impaired schizophrenia. Acta Psychiatr Scand. 2003;108(2):101-9.

17. Bell MD, Fiszdon J, Bryson G, Wexler BE. Effects of neurocognitive enhancement therapy in schizophrenia: Normalisation of memory performance. Cognit Neuropsychiatry. 2004;9(3):199-211.

18. Fiszdon JM, Bryson GJ, Wexler BE, Bell MD. Durability of cognitive remediation training in schizophrenia: Performance on two memory tasks at 6-month and 12-month follow-up. Psychiatry Res. 2004;125(1):1-7.

19. First MB, Spitzer RL, Gibbon M, Williams JB. Structured Clinical Interview for DSM-IV Axis I Disorders-Patient Edition (SCID-I/P). Version 2.0. New York (NY): New York State Psychiatric Institute, Biometrics Research Department; 1996.

20. Bryson GJ, Bell MD, Lysaker PH, Zito W. The Work Behavior Inventory: A scale for the assessment of work behavior for people with severe mental illness. Psychiatr Rehabil J. 1997;20(4):47-55.

21. Bryson GJ, Bell MD, Greig T, Kaplan E. The Work Behavior Inventory: Prediction of future work success of people with schizophrenia. Psychiatr Rehabil J. 1999;23(2):113-17.

22. Greig TC, Bryson GJ, Bell MD. Development of a scale for the assessment of cognitive impairments in vocational 
rehabilitation: reliability and predictive validity. $\mathrm{J}$ Vocat Rehabil. 2004;21:71-81.

23. Bracy O. CogReHab Software. Indianapolis (IN): Psychological Software Services; 1995.

24. Ben-Yishay Y, Rattok J, Lakin P, Piasetsky EG, Ross B, Silver S, Zide E, Ezrachi P. Neuropsychological rehabilitation: Quest for a holistic approach. Sem Neurol. 1985;5:252-59.

25. Wexler BE, Anderson M, Fulbright RK, Gore JC. Preliminary evidence of improved verbal working memory performance and normalization of task-related frontal lobe activation in schizophrenia following cognitive exercises. Am J Psychiatry. 2000;157(10):1694-97.

26. Wykes T, Reeder C, Corner J, Williams C, Everitt B. The effects of neurocognitive remediation on executive processing in patients with schizophrenia. Schizophr Bull. 1999;25(2):291-307.

27. Reeder C, Newton E, Frangou S, Wykes T. Which executive skills should we target to affect social functioning and symptom change? A study of a cognitive remediation therapy program. Schizophr Bull. 2004;30(1):87-100.

28. Velligan DI, Prihoda TJ, Ritch JL, Maples N, Bow-Thomas CC, Dassori A. A randomized single-blind pilot study of compensatory strategies in schizophrenia outpatients. Schizophr Bull. 2002;28(2):283-92.

29. Velligan DI, Bow-Thomas CC, Huntzinger C, Ritch J, Ledbetter, N, Prihoda TJ, Miller AL. Randomized controlled trial of the use of compensatory strategies to enhance adaptive functioning in outpatients with schizophrenia. Am J Psychiatry. 2000;157(8):1317-23.

30. McQuaid JR, Granholm E, McClure FS, Roepke S, Pedrelli P, Patterson TL, Jeste DV. Development of an integrated cognitive-behavioral and social skills training intervention for older patients with schizophrenia. J Psychother. 2000; 9(3):149-56.

31. Granholm E, McQuaid JR, McClure FS, Pedrelli P, Jeste DV. A randomized controlled pilot study of cognitive behavioral social skills training for older patients with schizophrenia. Schizophr Res. 2002;53(1-2):167-69.

32. Hogarty GE, Flesher S, Ulrich R, Carter M, Greenwald D, Pogue-Geile M, Kechevan M, Cooley S, DiBarry AL, Garrett $\mathrm{A}$, Parepally $\mathrm{H}$, Zoretich $\mathrm{R}$. Cognitive enhancement therapy for schizophrenia: Effects of a 2-year randomized trial on cognition and behavior. Arch Gen Psychiatry. 2004;61(9):866-76.
33. Hogarty GE, Flesher S. Practice principles of cognitive enhancement therapy for schizophrenia. Schizophr Bull. 1999;25(4):693-708.

34. Wiedl KH. Rehab rounds: Cognitive modifiability as a measure of readiness for rehabilitation. Psychiatr Serv. 1999;50(11):1411-13,1419.

35. Wiedl KH, Schottke HH, Garcia MDC. Dynamic assessment of cognitive rehabilitation potential in schizophrenic persons and in elderly persons with and without dementia. Eur J Psychol Assess. 2001;17(2):112-19.

36. Wiedl KH, Wienobst J. Interindividual differences in cognitive remediation research with schizophrenic patientsIndicators of rehabilitation potential? Int J Rehabil Res. 1999;22(1):55-59.

37. SAS Version 8.2. Cary (NC): SAS Institute; 2001.

38. Davis LD, Lysaker PH, Lancaster RS, Bryson GJ, Bell MD. The Indianapolis Vocational Intervention Program: A cognitive behavioral approach to addressing rehabilitation issues in schizophrenia. J Rehabil Res Dev. 2005;42(1):35-45.

39. Lysaker PH, Bryson GJ, Marks K, Greig TC, Bell MD. Coping style in schizophrenia: Associations with neurocognitive deficits and personality. Schizophr Bull. 2004;30(1):113-21.

40. Lysaker PH, France CM. Psychotherapy as an element in supported employment for persons with severe and persistent mental illness. Psychiatry. 1999;62(3):209-21.

41. Lysaker PH, Lancaster RS, Lysaker JT. Narrative transformation as an outcome in the psychotherapy of schizophrenia. Psychol Psychother. 2003;76(Pt3):285-99.

42. Spaulding WD, Sullivan ME, Poland JS. Treatment and Rehabilitation of Severe Mental Illness. New York (NY): Guilford Press; 2003.

43. Bond GR, Becker DR, Drake RE, Rapp CA, Meisler N, Lechman AF, Bell MD, Blyler CR. Implementing supported employment as an evidence-based practice. Psychiatr Serv. 2002;52(3):313-22.

44. Greig TC, Zito W, Wexler BE, Bell MD. Effects of cognitive remediation on supported employment: A randomized clinical trial [abstract]. Schizophr Bull. 2005;31(2)525.

45. Greig TC, Wexler BE, Bell MD. Cognitive training in schizophrenia: neuropsychological and functional improvements [abstract]. Biol Psychiatry. 2004;55(8 Suppl 1):172.

Submitted for publication March 17, 2005. Accepted in revised form July 12, 2005. 